\title{
Estabilidade monetária e CEPAL: A heterogeneidade do pensamento estruturalista latino-americano ${ }^{1}$
}

\author{
Monetary stability and ECLAC: the heterogeneity \\ of developmental structuralist doctrine of Latin America
}

PEDRO LUIZ APRIGIO

ANDRÉ RONCAGLIA DE CARVALHO ${ }^{2 a}$

\begin{abstract}
RESUMO: O artigo verifica a hipótese de homogeneidade estrita do pensamento estruturalista latino-americano em matéria de estabilidade monetária em seus anos iniciais. Em meados da década de 1950, o crescente e contínuo fenômeno inflacionário na região era explicado pela CEPAL como resultante da presença de estrangulamentos nas estruturas reais da economia. Entretanto, o canal de transmissão ao nível de preços é explicado pelos autores de maneiras diversas, gerando-se, por conseguinte, diferentes propostas de estabilização. $\mathrm{O}$ artigo sublinha a flexibilidade metodológica e o grau de fragmentação teórica da abordagem cepalina, bem como a controvérsia sobre a inflação constituir parte do processo de desenvolvimento. A análise destes elementos revela uma tensão entre os aspectos keynesianos anglo-saxônicos na abordagem de Prebisch e a original teoria latino-americana proposta por Noyola e Furtado. Avalia-se em que medida este descompasso impediu a constituição de um corpo teórico diferenciado em matéria de estabilização monetária.

PALAVRAS-CHAVE: Estruturalismo latino-americano; inflação estrutural; estabilização monetária; CEPAL, heterogeneidade metodológica.
\end{abstract}

\footnotetext{
${ }^{1}$ Este trabalho deriva da pesquisa de Iniciação Científica na Fundação-Escola de Comércio Alvares Penteado (FECAP) do autor principal e teve versão anterior aprovada para apresentação no $4^{\text {th }}$ Latin American Meeting of the European Society for the History of Economic Thought - ESHET, em Belo Horizonte - Minas Gerais, bem como no encontro nacional de economia de 2015 promovido pela ANPEC na cidade de Florianópolis, Santa Catariana.

${ }^{2}$ Graduado em Economia - Centro Universitário FECAP. E-mail: plaprigio@gmail.com.

${ }^{2 a}$ Professor Adjunto do Departamento de Economia da Escola Paulista de Política, Economia e Negócios - EPPEN, Universidade Federal de São Paulo (UNIFESP), Campus Osasco. E-mail: andre.carvalho@ unifesp.br. Submetido: 14/Junho/2016; Aprovado: 10/Abril/2017.
} 
ABSTRACT: The paper evaluates the assumption of a homogeneous theory of monetary stabilization in early Latin American structuralist economics. Starting in the 1950s, the growing and continuous inflationary problem in the region was seen as a result of bottlenecks within the productive structure. However, the channels that transmit such imbalances onto prices are framed quite distinctly amongst the aforementioned writers, with implications regarding their policy suggestions. The paper underlines a methodological flexibility, which engendered a fragmented theoretical framework of analysis, and the notion that inflation was part of the process of economic development. The combination of both elements unveiled an analytical deficiency within ECLA's theory of monetary stabilization. As a result, there arose a tension between Prebisch's Anglo-Saxon Keynesian view and the original theory proposed by Noyola and Furtado. The paper traces the nature of such disparities and the extent to which they impaired the constitution of a unique theoretical corpus on matters of stabilization.

KEYWORDS: Latin American structuralism; structural inflation; monetary stabilization; ECLA; methodological heterogeneity.

JEL Classification: B25, B30.

\section{INTRODUÇÃO}

Em meados da década de 1950, o crescente e contínuo fenômeno inflacionário na região era explicado, pela CEPAL, como resultado da presença de estrangulamentos na estrutura real da economia. A nova e original corrente de pensamento sobre inflação recebeu as principais contribuições de J. Noyola Vázquez, C. Furtado e O. Sunkel, além das bases fornecidas por Raúl Prebisch. Parte da literatura tem concentrado suas atenções nas trajetórias individuais ou no desenvolvimento da teoria estruturalista da inflação. Por exemplo, Craven (1994) já demonstrou que Noyola passara por uma conversão à heterodoxia no início dos anos 1950, o que a autora chamou de "o problema da transformação estruturalista". Por outro lado, a suposição de que esse pensamento atingira suficiente grau de consolidação nos anos 1960 levanta uma interessante pergunta quanto às suas origens, motivação central deste artigo, a saber: verificar a hipótese de uma adesão irrestrita a um arcabouço de ideias em comum ligadas a efetividade de medidas de estabilização monetária no combate à inflação por parte dos pensadores seminais do estruturalismo latino-americano. Tal discussão é iniciada em importantes trabalhos deste campo, como em Boianovsky (2012), Boianovsky \& R. Solís (2014), Danby (2005), entre outros a serem citados.

$\mathrm{O}$ artigo está dividido em três partes, além desta introdução. A segunda seção faz uma descrição relativamente esquemática de parte das contribuições de Prebisch, Furtado e Noyola. A terceira aprofunda de forma sistemática o problema da heterogeneidade das propostas analíticas desses autores, buscando revelar tensões que perpassam os planos metodológico, teórico e histórico-institucional do problema. A última seção conclui o artigo. 


\section{ESTRUTURALISMO, CEPAL E AS ABORDAGENS SOBRE A INFLAÇÃO}

A ascensão de Raúl Prebisch ao cargo de secretário-geral da CEPAL marca a criação do que podemos caracterizar como o pensamento desenvolvimentista latino-americano. Nos textos produzidos entre 1949 e 1951, em especial, temos a definição dos pressupostos básicos pelos quais argumentaria a CEPAL ao longo da década de 1950. Já em seu "Manifesto" (1949) Prebisch formula a principal crítica ao chamado sistema centro-periférico, que consiste na observação de que ao longo do tempo a relação de preços tornou-se cada vez mais favorável aos bens de consumo industrializados, enquanto paralelamente os ganhos de produtividade na periferia não se equiparavam aos aumentos de produtividade no centro. Em prol dos padrões de consumo, em especial do consumo de luxo, a necessidade de importação de manufaturados racionaliza uma tendência crônica a crises no balanço de pagamentos, com consequentes desvalorizações cambiais.

Aliado a este fenômeno, observava-se uma assimetria entre o poder de barganha dos trabalhadores nos países centrais - mais organizados em torno da rigidez dos salários à baixa - e aqueles das economias periféricas, menos organizadas e, por conta da relativa elasticidade da mão de obra, mais vulneráveis ao desemprego durante a purga recessiva do ciclo econômico.

Interestingly enough, Prebisch (1949) who was dealing with the problems of economic expansion in the periphery was, from a normative point of view, concerned with wage-led growth. Note that his explanation for the tendency of terms of trade of commodities to fall over time (the so-called Prebisch-Singer hypothesis) was based on the fact that in the boom wages went up in the center, but not so much in the periphery, since industrial workers in the center were organized and could demand higher salaries, while that was not possible for the agricultural and mining workers in the periphery. So in the recession, while prices of commodities and wages fell in the periphery, they did not collapse in the center. Bargaining power and not just technological change, was at the heart of the asymmetries between the center and the periphery (CALDENTEY e VERNENGO, 2013, p. 9, nota de rodapé).

A superação destes problemas, que caracterizam a condição periférica, reside no próprio processo de industrialização, na medida em que, ao aumentar o poder de barganha dos trabalhadores de forma consistente, tornará os salários na periferia mais resistentes às pressões baixistas - oriundas do ciclo econômico internacional e dos efeitos de propagação deste sobre a distribuição interna da renda - e, portanto, impossibilitará a apropriação dos excedentes em prol do consumo de luxo ${ }^{3}$. Por outro lado, a especialização na produção de bens industriais neutraliza-

\footnotetext{
${ }^{3}$ Prebisch argumenta que as classes mais abastadas buscavam o consumo de certos bens industriais não
} 
rá os efeitos perversos sobre o balanço de pagamentos. Como resultado, espera-se um acúmulo de poupança consistente com um maior nível de inversão com baixa dependência de financiamento via poupança externa ou meios inflacionários.

Quanto à questão inflacionária, Prebisch a associava a pressões de demanda ligadas ao descolamento entre a produtividade do trabalho e seu nível real de salários. Isso se deve à expansão do meio circulante que iniciou o processo inflacionário ao gerar uma elevação da renda monetária. $\mathrm{O}$ autor não negava o impacto dos desequilíbrios estruturais, mas destacava o primordial papel de sobrecargas de demanda, uma vez ocupada a capacidade ociosa dos fatores de produção. Esta análise seguia o conceito de "hiato inflacionário", de corte tipicamente keynesiano. Sob as específicas peculiaridades das distintas circunstâncias ${ }^{4}$, Prebisch se alinhava a Keynes em suas críticas a racionalização de pressões de demanda através da emissão monetária ${ }^{5}$, realizada para financiar o desbalanceamento entre as receitas e despesas do Estado ${ }^{6}$. Dessa forma, ainda que houvesse causas estruturais para a inflação, o autor debitava as pressões mais relevantes à conta do comportamento por vezes pouco responsável das autoridades em financiar os gastos estatais via emissão primária e na lassidão dos controles sobre a expansão do crédito $^{7}$ (PREBISCH, 1949, [2000], p. 111).

Tal visão de Prebisch sobre o funcionamento dos mecanismos monetário é fundamental para a conclusão de sua interpretação sobre a efetividade da política de estabilização monetária como meio de combate a inflação, sendo o bojo de suas discordâncias ante a inovadora análise estruturalista:

Contrary to a widespread belief the writings of Raúl Prebisch do not belong to the structuralist school; one of this school's basic tenets is

\footnotetext{
produzidos localmente. Isso ocasionava um desvio deste excedente para a importação oriunda dos grandes centros industriais. Para uma argumentação formal do "excedente econômico" e sua relação com consumo de luxo, ver Prebisch (1982).

${ }^{4}$ Enquanto o Reino Unido de Keynes estava focado no "esforço de guerra", a América Latina cepalina passava por um período ideológico pautado na ideia de "esforço pelo desenvolvimento".

5 “A inflação do sistema monetário europeu já avançou extraordinariamente. Incapazes por timidez ou miopia de obter com impostos ou empréstimos os recursos de que precisavam, os governos beligerantes recorriam à impressão de papel-moeda" (Keynes, 1919 [2002], p. 165).

${ }^{6}$ A questão sobre como sanar a necessidade de financiamento do Estado sem gerar pressões inflacionárias preenche uma significativa parcela da obra de Prebisch, especialmente em relação ao financiamento externo. A expansão creditícia falha ao viabilizar a elevação dos custos sem afetar a apropriação da poupança para o consumo de luxo, mantendo assim a escassez de poupança, determinada pela estrutura produtiva periférica. Questão próxima é também foco da análise de Keynes em seu "How to pay for the war" (1940, p. 57), onde propõe a utilização de política de poupança compulsória, alternativa ao financiamento inflacionário do governo e a futura deterioração da distribuição da renda, uma vez que os rentistas detentores dos títulos da dívida pública venham a aumentar a sua riqueza com a subsequente elevação dos juros.

${ }^{7}$ Como argumenta C. Danby (2005, p. 2), "ECLA's approach to money, credit, and inflation is therefore quite distinct from the theory put forward in Noyola 1956".
} 
the passive character of money, whereas Prebisch is a firm believer in the effectiveness of monetary policy" (PAZOS, 1972c, pp. 10-11).

Na visão de Celso Furtado (2009, pp.161) a narrativa assume outra estrutura: a inflação é um sintoma histórico do estágio de desenvolvimento das forças produtivas e das relações sociais de produção (ou, instituições, em termos contemporâneos). O subdesenvolvimento é um processo histórico autônomo, ligado à estruturação dualista que se formou nas economias periféricas latino-americanas. Estas estruturas sofrem com os fortes desequilíbrios no setor produtivo, determinantes nos desajustes que levam a alta dos preços relativos e ao desequilíbrio do balanço de pagamentos. Sendo assim, a superação do subdesenvolvimento nestes países está fundamentalmente atrelada à capacidade de seus estados em viabilizar as inversões de capital em prol do processo de industrialização e superação dos estrangulamentos estruturais.

No entanto, a transformação estrutural carregava em seu bojo fortes pressões inflacionárias: dada a insuficiente capacidade de obter recursos através da exportação, a industrialização levava ao aumento relativo do preço dos bens importados, pressionando a inflação. Adicionalmente, aliada às necessidades do desenvolvimento, uma reprimida demanda social por serviços básicos (educação, saúde etc.) "concorria" com a formação de capital pelo uso dos recursos disponíveis. Em face da inércia institucional e da miopia das elites econômicas, as políticas fiscal e tributária de países subdesenvolvidos padecem de desequilíbrios estruturais, de maneira que a tributação regressiva e ineficiente era incapaz de acompanhar os crescentes dispêndios públicos ao longo do processo de desenvolvimento (FURTADO, 1959c, p. 136). A falta de capacidade de financiamento do déficit público, aliado ao aumento da demanda de meio circulante por parte da sociedade, acaba por conduzir a autoridade monetária a racionalizar a expansão creditícia, de modo a evitar uma possível crise de liquidez. Observa-se assim a característica endógena assumida pela oferta de moeda.

Ponto altamente controverso na análise furtadiana reside na possibilidade de um processo inflacionário sancionar o desenvolvimento econômico e a própria busca por estabilidade ${ }^{8}$. Em casos de choques conjunturais ou movimentos cíclicos, que levam à elevação dos preços do produto primário de especialização no mercado externo, observam-se elevação no nível de renda e uma consequente pressão sobre a demanda. Caso a política cambial deste país esteja voltada ao projeto de desenvolvimento, dificulta-se a importação de bens de consumo promovendo paralelamente maior facilidade na importação de bens de inversão. Dada a estrutura de apropriação do excedente que está voltado em grande parte ao consumo de luxo, observa-se a elevação dos preços da indústria nacional e o barateamento re-

\footnotetext{
${ }^{8}$ Em participação de debate sobre a explanação do clássico artigo de Noyola Vázquez (1956) "El Desarrollo Económico y La Inflación en México y otros Países Latinoamericanos” o autor se refere ao ciclo inflacionário brasileiro iniciado em 1949 com a alta dos preços do café.
} 
lativo da importação de capital. A melhoria da rentabilidade interna da indústria induz à taxa de crescimento das inversões e a subsequente aceleração do processo de desenvolvimento 9 . Todavia, o benefício distributivo estaria restrito a esta fase inicial do processo, de forma que se não for devidamente disciplinada, a inflação pode degenerar-se em um processo em que os grupos sociais tentam transferir o ônus do ajuste entre si, tornando-se um processo inteiramente estéril do ponto de vista distributivo.

Assim, parte desta inflação findará sendo inerente ao próprio processo de superação dos estrangulamentos estruturais da oferta, via a transferência do centro dinâmico para a produção industrial. Por isso, utilizar políticas ortodoxas de estabilização monetária pode implicar não apenas em fracasso em desinflacionar como pode estancar o crescimento econômico, gerando efeitos duplamente indesejáveis do ponto de vista do desenvolvimento.

É inadequado, todavia, creditar aos estruturalistas sentimentos inflacionistas inatos, uma vez que enxergar efeitos colaterais positivos não implica endossar qualquer nível de inflação ou mesmo políticas consistentemente inflacionárias. Ao contrário, aos olhos de Furtado, o desafio da política anti-inflacionária consiste em não prejudicar o desenvolvimento econômico ao desinflacionar os preços, haja vista que as causas deste fenômeno encontram-se nas incontornáveis pressões primárias - oriundas da baixa elasticidade da oferta de bens agrícolas e da sensibilidade dos bens intermediários importados a variações na taxa de câmbio - e nos mecanismos de propagação decorrentes dos conflitos distributivos e da rigidez institucional do aparato fiscal do Estado.

Ao reverter a causalidade clássica entre moeda e preços, Furtado propõe uma teoria distributiva da inflação densa em mecanismos institucionais e estruturais, os quais se desenrolam dinamicamente no tempo histórico à mercê da disputa entre as forças sociais pelo controle da política econômica. Ao partir do entendimento, na linha de Aujac ([1950] 1954), de que é o poder relativo entre as frações da sociedade que determina o perfil das relações monetárias, a elevação constante do nível de preços não passa de um mecanismo de transferência de renda dos menos para os mais dotados de poder político e econômico. Cabe ao Estado - e, portanto, à política econômica - direcionar as tensões dentro dessa rede de orçamentos monetários individuais rumo ao aprimoramento endógeno das forças produtivas da economia. Para Furtado - e, como veremos a seguir, para Noyola - a estratégia de estabilização ortodoxa controla a inflação (um sintoma de curto prazo) à custa de desarmar os motores da transformação estrutural (um processo de longo prazo).

Juan Noyola Vázquez foi o primeiro a desenvolver uma síntese formal para as ideias recém-elaboradas pelos jovens cepalinos sobre o problema da inflação da

\footnotetext{
${ }^{9}$ Como argumenta Furtado, “[...] a inflação não gerava recursos, apenas modificava o perfil de apropriação dos novos recursos gerados pela melhora na relação de trocas”. E ainda é enfático ao afirmar que "[...] sem a inflação ter-se-iam diluído em incremento do consumo (principalmente dos grupos de rendas altas e médias) os recursos gerados pela melhora na relação de trocas” (FURTADO, 1985, pp. 179-180).
} 
América Latina (Bielschowsky, 1995, pp. 23-24). Sua abordagem parte do princípio fundamental de que a inflação não é um fenômeno monetário, sendo, na verdade, fruto de desequilíbrios reais da economia. Mesmo sendo uma análise de cunho econômico destaca-se o aspecto "social" e "institucional" que acrescentava aos fenômenos em sua abordagem, em especial em suas observações sobre a inflação ${ }^{10}$. Sua ampla consideração sobre aspectos que vão desde as disparidades setoriais e o grau de monopolização até a organização sindical e a distribuição do poder político entre as classes o levou ao que se chamou de desequilíbrios estruturais. Assim o processo inflacionário nada mais é do que o fruto destes desequilíbrios e do modo como interagem entre si.

Um primeiro grupo é formado pelas pressões estruturais, em especial os desequilíbrios estruturais dinâmicos, como a disparidade entre o crescimento do setor agropecuário para consumo interno e o crescimento da demanda populacional, em especial nos centros urbanos e o encarecimento da produção interna dada sua dependência dinâmica da insuficiente capacidade de importação para inversões produtivas. Esses desequilíbrios levam ao desnível dos preços relativos. São as chamadas pressões inflacionárias básicas. $\mathrm{O}$ segundo grupo trata de fatores capazes de potencializar e alastrar o aumento relativo dos preços pela economia, os chamados mecanismos de propagação. Embora estes existam em variada gama, Noyola enfatiza em sua análise três pontos que possuem grande importância. São eles (1) o mecanismo fiscal, em especial por seu caráter regressivo (inclui-se aqui a previdência social e os subsídios cambiais), (2) o mecanismo de reajuste de preços e rendas e (3) o mecanismo creditício.

Embora a análise do autor sobre os pontos de pressão primária tenha grande valor ao sintetizar uma gama de estudos cepalinos sobre o tema, a principal contribuição de seu trabalho é a inovadora abordagem dos mecanismos de propagação. Nesta, os diferentes impactos da elevação dos preços sobre uma sociedade podem ser explicados pela maneira como determinadas classes conseguem manter sua participação na renda através da redução da parcela destinada à classe mais frágil (DANBY, 2005, p. 11).

Es evidente que si la intensidad (de la inflación) se mide en términos del aumento de los precios, la inflación de Chile se lleva la palma; pero si se acepta que la inflación es una lucha entre los diversos grupos sociales por mejorar o mantener su participación en el ingreso nacional, la inflación mexicana revela tener consecuencias distributivas mucho más profundas (NOYOLA VÁZQUEZ, 1956, p. 70).

\footnotetext{
${ }^{10}$ Esta característica na análise de Noyola está ligada à influência do texto de Aujac ([1950] 1954), que destaca a inflação como uma expressão do conflito distributivo. Além deste texto, podemos citar a influência de Kalecki (NOYOLA VÁZQUEZ, 1956, p. 2), muito embora sua análise vá além das propostas por tais autores.
} 
De modo geral, quando temos fortes pressões inflacionárias básicas, o que se observa é a alta galopante dos preços. Contudo, através de políticas bem focadas é possível o controle dos mecanismos de propagação que, caso não sejam contidos, acentuam a concentração de renda, o que é muito mais nocivo ao processo de desenvolvimento.

Outro aspecto importante da obra de Noyola Vázquez é a interpretação do estado como agente passivo em muitos aspectos da política econômica, inclusive na condução da política monetária. Seu controle por parte de grupos sociais de grande poder político e econômico tornava-o ferramenta para busca dos interesses de classes em meio ao conflito distributivo, em especial, o caso em que promoviam expansões na oferta de moeda a fim de dar liquidez para os aumentos de preços, por eles propostos (DANBY, 2005, p. 13). Uma característica institucional inerente às estruturas periféricas é a pequena margem de poder de barganha conquistada pelos trabalhadores. Dada à elasticidade na oferta deste fator produtivo, grande parte do poder econômico estava nas mãos da classe que controlava a produção do setor de atividade com maior dinamismo, fundamentalmente, primário-exportador.

\section{A HETEROGENEIDADE DO PENSAMENTO CEPALINO SOBRE INFLAÇÃO E ESTABILIDADE MONETÁRIA}

Nesta seção analisamos, de forma mais detida e menos esquemática, as diferenças nos quadros teóricos propostos pelos autores, buscando elencar as principais forças que produziram tensões internas às seminais formulações analíticas cepalinas. São tratadas, nessa ordem, questões metodológicas, teóricas e históricas.

\section{Aspectos Metodológicos}

Colistete (2007) defende que, nos primeiros anos de atividade intelectual da CEPAL, houve uma ausência ou imprecisão na formulação das hipóteses centrais de modo a torná-las bem definidas. Contudo, para o autor, esta perspectiva se mostra fundamental para o sucesso da doutrina cepalina, dado que desta maneira adquiriu fluidez, ao permitir que alguns aspectos fossem repensados ou incrementados ao longo do tempo sem que se ferissem seus postulados originais.

Para nossa análise, o ponto mais importante é que esta não especificação acabou por abrir margem para as divergências metodológicas na abordagem de algumas hipóteses, culminando nas diferentes propostas sobre a estabilidade monetária e a inflação que se confrontaram no seio da CEPAL nos decênios de 1950 e 1960 (FURTADO, 1985, p. 182).

Uma característica inovadora da abordagem estruturalista era uma análise "microfundamentada" em prol de respostas para uma problemática de ordem macroeconômica, contribuição inicialmente incorporada nos escritos de Furtado (BOIANOVSKY, 2012, p. 10). Este aspecto é fundamental para o avanço de passagens da teoria estruturalista, como o caráter não agregativo da inflação, sendo 
esta originária de desajustes setoriais que levam à alteração de preços relativos. Outra característica marcante na abordagem cepalina era a percepção de uma dualidade fundamentalmente conflituosa dos problemas econômicos (JAMESON, 1986, pp. 233-234) ${ }^{11}$.

Em contraste com essa posição, Prebisch possuía uma visão mais agregativa das variáveis macroeconômicas, muito ligada à abordagem keynesiana. Esta diferença impossibilita a Prebisch a percepção fragmentada da inflação e o modo como esta se origina de desnivelamentos setoriais e no movimento desequilibrado dos preços relativos. Os efeitos da inflação (fruto de uma pressão de demanda agregada) não possuem consequências distintas para cada setor específico onde se encontram de desequilíbrios, assumindo-os como verdadeiros. A utilização de políticas monetárias restritivas, portanto, teria maior efetividade do que pregava a doutrina estruturalista, ao liquidar com o mal inflacionário e permitir a continuidade do desenvolvimento. Por outro lado, a flexibilidade metodológica da abordagem cepalina permitiu, ainda, que Prebisch acomodasse questões que não habitavam o corpo central de sua argumentação inicial, presente no "manifesto latino-americano". Neste sentido, esta "margem de manobra", ressaltada por Colistete (2007), foi fundamental para que Prebisch conseguisse alinhar as recomendações de atuação político-econômica em países cujo apoio era fundamental para a continuidade da CEPAL.

\section{Tensões Teóricas}

Muito embora Prebisch admitisse a presença de tensões estruturais sobre os preços, enxergava o problema inflacionário como a resultante da prática desregulada de financiar o déficit estatal através de emissão primária. Embasado em aspectos fundamentais da análise keynesiana, tinha visão estrita dos danos causados à distribuição da renda e do modo como a inflação se contrapunha ao projeto do desenvolvimento. Uma vez que as atrasadas relações de produção dos países subdesenvolvidos estavam no cerne do conflito distributivo (tendo seus efeitos ainda agravados pela inflação na medida em que as classes mais elevadas tentam manter seu excedente voltado para o consumo de luxo) e que a solução para as relações de caráter periférico dos fatores de produção está na própria modernização vinda com a industrialização, o combate ao problema inflacionário é ponto-chave no processo de desenvolvimento econômico. Fundamenta-se assim sua posição em prol de choques de contenção monetária a fim de rapidamente liquidar a acelerada elevação dos preços e dar continuidade à modernização econômica e social.

Já a visão estruturalista de Furtado e Noyola explicava a inflação como resultante de tensões estruturais profundas, em especial a restrição dinâmica imposta pela capacidade de importação expressa nas diferentes relações de produção entre

\footnotetext{
${ }^{11} \mathrm{O}$ termo "estruturalista" aqui empregado se refere ao conjunto de pensadores da CEPAL, não sendo similar à diferenciação feita em PAZOS (1972, pp. 10-11)
} 
o centro e a periferia, que levavam à deterioração dos termos de troca (conforme estabelecido pelo próprio Prebisch como base fundamental do pensamento desenvolvimentista cepalino) e o consequente desequilíbrio crônico do balanço de pagamentos. Estes pontos de pressão eram a causa da alta desordenada dos preços relativos, que, dado o caráter endógeno dos mecanismos de propagação, levavam à elevação geral dos preços. Portanto, uma política de estabilização monetária seria ineficaz na medida em que não afeta a verdadeira raiz de tal fenômeno. A solução para este problema estaria na própria superação do subdesenvolvimento, que naturalmente viria a dar cabo dos estrangulamentos setoriais da oferta, aliviando as pressões altistas sobre os preços relativos. Quanto ao curto prazo, qualquer medida em questão não deveria nunca se opor aos objetivos do desenvolvimento, gerando ociosidade da capacidade produtiva e, consequentemente, a recessão econômica. Aliadas a isso, políticas voltadas ao combate da regressividade dos mecanismos de propagação são medidas possíveis, de modo a conter o acirramento do conflito distributivo latente. Em especial, através do aumento de transferências estatais, neutralizando os efeitos da tributação, que nos países da América Latina faz recair sobre os ombros das classes mais baixas o ônus do aumento inflacionário dos tributos.

O debate sobre estas medidas, tanto restritivas quanto distributivas, perpassa pela visão entre os autores sobre o funcionamento do Estado. Na visão estruturalista um elevado grau de passividade era visto na condução governamental. Tal concepção pautava-se na observação da desigual distribuição do poder político entre as camadas da sociedade, concentrando a influência decisória entre as elites ligadas à produção primário-exportadora. Orquestravam a condução dos sistemas monetário, financeiro e fiscal em virtude da prosperidade de seus negócios. A própria política monetária em si estaria voltada a conferir liquidez as medidas tomadas em meio ao conflito distributivo e ao aumento das demandas sociais (DANBY, 2005). Em contraste, Prebisch não se detinha sobre a composição do Estado em si, uma vez que havia desenvolvido uma visão de um setor público altamente técnico, comprometido com o desenvolvimento da nação, e que não se empenhava em prol de nenhuma das partes do conflito social.

During his years in the Central Bank he had evolved a concept of the "intelligent state" which he described as "a lean but strong public sector, capable of defining overall orientations for national development and supporting the private sector rather than suffocating its dynamism (DOSMAN, 2012, p. 13).

Sua visão de Estado estava muito embasada na capacidade transformadora vista em List ${ }^{12}$, que viabilizava de certa forma seu argumento sobre a industrialização via substituição de importações, guiada pelo Estado, dada a incapacidade de

${ }^{12}$ Sobre a influência de List no pensamento cepalino ver Fonseca (2000, p. 352). 
transformações guiadas pelo livre mercado. Assumir este elevado grau de capacidade estatal está estritamente associado aos projetos de Prebisch para a América Latina, sendo estas ideias o centro orbital da doutrina cepalina.

\section{Aspectos Histórico-Institucionais: formação e consolidação da CEPAL}

Em meio aos debates do nascente Conselho Econômico e Social das Nações Unidas, um dos pontos de maior controvérsia girava em torno da criação de uma comissão específica para a América Latina. Os países pertencentes a esta região ressaltavam que, mesmo estando geograficamente distantes das regiões de conflito em si, haviam sofrido efeitos diretos da queda no nível de atividade econômica global, observado desde a Grande Depressão, uma vez que o ponto fundamental para a estabilidade de suas economias estava diretamente ligado aos recursos obtidos por meio do comércio internacional. Assim, mesmo com forte oposição ${ }^{13}$, os países latino-americanos conseguiram articular a criação de uma comissão (de caráter não permanente) voltada para o desenvolvimento de estudos de caráter prático, com o objetivo de fornecer as melhores estratégias para a recuperação econômica da região:

[...] facilitar la acción concertada para reconstrucción económica [...] elevar el nivel de actividad económica de [...] y mantener y reforzar las relaciones económicas de los países [...] tanto entre sí como con otros países del mundo. [...] La comisión tiene la facultad de formular recomendaciones sobre cualquier asunto de su competencia, directamente a sus gobiernos miembros y a los organismos especializados. (SANTA CRUZ, 1984, pp. 125 apud MALLORQUÍN, 2008, p. 8)

Muito embora o início dos trabalhos na CEPAL tenha ocorrido em meados de 1948, foi com a publicação do chamado "manifesto latino-americano" em 1949 e a subsequente ascensão de Prebisch ao secretariado-geral, em maio de 1950, que a posição cepalina sobre a defesa da industrialização como o único caminho para alcançar os avanços necessários à região é elaborada de forma mais clara e enfática ${ }^{14}$.

Como ressalta Furtado (2014, pp. 88), desde seu início, a instituição teve de escolher entre "[...] defender uma industrialização surgida em condições anormais,

\footnotetext{
${ }^{13}$ Dois fortes grupos de opositores se fizeram presentes. O primeiro era composto pelos países europeus que acreditavam piamente em uma perda do objetivo inicial do encontro (a reconstrução das zonas devastadas pela guerra), acarretando no desvio dos recursos disponibilizados pelos novos mecanismos de fomento e financiamento internacionais (Banco Internacional de Reconstrução e Desenvolvimento, FMI etc.). A segunda força opositora eram os norte-americanos, que, nas palavras de Furtado (2014, p. 85), “[...] se esforçavam por preservar a América Latina como área de influência própria no quadro da Organização dos Estados Americanos (OEA)”, órgão em que possuíam forte influência ideológica e controle.

${ }^{14}$ Ainda em 1949, o recém-formado grupo de economistas cepalinos pôde apresentar suas novas ideias na conferência realizada em Havana.
} 
por muitos considerada 'artificial', de 'altos custos', ou preconizar a volta metódica ao quadro das vantagens comparativas em que se havia fundado o desenvolvimento antes do crash de 1929".

As seminais ideias propostas pela CEPAL puderam ser defendidas ante a abordagem ortodoxa, representada pela delegação norte-americana, durante as conferências programadas entre 1949 e 1951 (realizadas respectivamente em Havana, Montevidéu e Cidade do México). Dentre os eventos deste período, cabe mencionar o impacto positivo do "Estudo Econômico da América Latina", apresentado em Montevidéu, que alcançou forte apoio entre os representantes dos governos latino-americanos. O estudo já era pautado nas proposições cepalinas ligadas ao problema da deterioração dos termos de intercâmbio e a subsequente restrição no balanço de pagamentos, bem como na necessidade de uma transformação nas relações produtivas guiada pelo Estado, em prol da superação da condição periférica ${ }^{15}$. Como consequência da receptividade alcançada, as delegações dos países da região firmaram um pacote comum de recomendações aos governos locais, o chamado Decálogo do Desenvolvimento Econômico, que tratava do modo como deveriam ser definidas as principais metas para o desenvolvimento econômico, bem como suas estratégias de implementação.

No entanto, é em 1951, com o fundamental "Problemas Teóricos e Práticos do Crescimento do Econômico", que o confronto entre os aspectos "centrais" da doutrina cepalina e a posição norte-americana se consolida. "Trata-se de um esforço de síntese de ideias que vinham sendo discutidas nos dois anos precedentes, delas derivando-se recomendações explícitas de política econômica" (FURTADO, 2014, p. 93). Mesmo mantendo-se "fiel” à sua posição inovadora no debate, ainda eram necessários cuidados quanto ao frágil apoio político que a CEPAL angariara na região. Neste aspecto, a visão prevalecente na instituição sobre a relação entre a inflação e o desequilíbrio externo, contrastadas à necessidade de crescimento, refletia na posição de Prebisch. Mesmo questionando a relação entre estas variáveis na abordagem ortodoxa, ainda argumenta que:

A inflação [...] tem nos países latino-americanos um papel dinâmico que se por um lado evidencia agudamente o desequilíbrio imanente do processo de crescimento, por outro tende a corrigi-lo. Mas ela o faz com um custo social considerável. E, em alguns casos, esse custo não tem relação com a escassa magnitude do efeito dinâmico obtido por meios inflacionários. Um dos problemas fundamentais do desenvolvimento econômico desses países consiste, precisamente, em estimular o crescimento sem chegar à inflação, e em prevenir o desequilíbrio com medidas oportunas de mudança na estrutura das importações. (PREBISCH, 2011 [1951], p. 279)

\footnotetext{
${ }^{15}$ Curiosamente, o tomo composto pelos cinco primeiros capítulos desse estudo, intitulado “Desequilíbrios e Disparidades: interpretação do processo de desenvolvimento econômico" foi escrito por completo pelo próprio Prebisch.
} 
Ainda no texto de 1951, critica a ideia vigente à época sobre a capacidade de financiar as transformações dinâmicas das economias periféricas por meios inflacionários, ideia que seria defendida por Furtado algum tempo depois (ver Furtado, 1954, p. 174).

Ao fim do encontro, mesmo sob nova investida norte-americana, o entusiasmo que as ideias cepalinas haviam alcançado em certos círculos foi fundamental para a decisão por sua continuidade e a consequente solidificação da existência da comissão como órgão permanente ${ }^{16}$. Comissão que agora, mais do que nunca, estava ligada ao desenvolvimento de ferramentas e métodos voltados a aplicação de políticas nos moldes da análise apresentada.

Com a margem de apoio alcançada, foi possível para Prebisch um distanciamento temporário de seus atributos como secretário-geral ${ }^{17}$. Este período, porém, acabou sendo marcado por grande desordem institucional, aliada a um clima de baixa motivação entre os funcionários, que sentiram a ausência da enfática liderança de Prebisch. Observou-se, ainda, uma redução no frágil apoio à existência da comissão, possibilitando a volta do questionamento sobre sua necessidade. As lideranças locais já se mostravam fatigadas de problemas e desenvolvimentos puramente teóricos, necessitando agora da sugestão de práticas que levassem "ao novo caminho", visto o esgotamento do surto de crescimento advindo no pós-guerra. "Os desafios do dia a dia, que os governos enfrentavam, tinham de substituir a teorização e as grandes intenções" (DOSMAN, 2011, p. 370). Este cenário findou em uma perda de espaço para questões que passaram a pauta central da organização, mas de caráter considerado acadêmico.

Prebisch reclamou que os funcionários haviam esquecido que o secretariado não era uma universidade, mas parte de uma comissão da ONU que respondia por seus atos perante os governos. A Cepal precisava manter as linhas abertas com os governos que estavam cansados de estudos, urgentes em 1949, ainda interessantes em 1951, mas desconsiderados como meramente acadêmicos em 1956. Estavam impacientes com o interminável debate interno sobre a inflação, por exemplo, se ela era “estrutural” ou não. (DOSMAN, 2011, p. 370)

Sua volta, em 1955, acaba sendo marcada pelo retorno a necessidade fundamental do apoio necessário entre os países da região, que agora passam a repensar sobre a decisão tomada no México, em 1951. No entanto, diferentemente do que se observou à época, as ideias do que chamamos de Estruturalismo, ligadas às abordagens seminais de Furtado e Noyola Vázquez, estavam agora em um novo patamar de maturidade, fornecendo maior oposição à aproximação de Prebisch aos argu-

\footnotetext{
${ }^{16}$ Em especial, o forte apoio alcançado junto aos governos brasileiro e chileno.

${ }^{17}$ Estava agora engajado na elaboração de um plano econômico que reorientasse a economia argentina no pós-Perón.
} 
mentos ortodoxos, defendidos principalmente pelo FMI, no que tangia ao combate da inflação. Prebisch se mostrava menos disposto do que seus colegas em aceitar a possibilidade de certo grau de inflação ser inevitável nas economias subdesenvolvidas, sendo ainda um fator de auxílio na alocação de maior parte da poupança total de forma mais eficiente pela ótica do processo de desenvolvimento. $\mathrm{Na}$ realidade, se mostra irredutível em relação à tolerância de certa margem de inflação.

Estou tão convencido do mal que a inflação faz aos países latino-americanos que, por questão de princípios, estou pouco inclinado a discutir medidas para corrigir certas consequências do processo inflacionário. Preferiria dedicar toda a nossa atenção à elaboração de uma política para cortar a inflação e estabilizar as economias sem prejudicar os incentivos ao crescimento econômico. (Carta de Prebisch a Nova York em DOSMAN, 2011, p. 368)

Já em sua visita ao Brasil na conferência de Quitandinha, em 1953, demonstra concordar com a necessidade de um combate intolerante à inflação defendido por Eugênio Gudin, mesmo discordando deste quanto à capacidade do livre mercado em promover a industrialização e as transformações necessárias para alcançar o desenvolvimento econômico (DOSMAN, 2011, p. 324).

Este combate à alta dos preços defendido por Prebisch consistia na intolerância para com comportamentos permissivos dos condutores da política econômica em financiar seus déficits através de emissões primárias. Em sua visão, dever-se-ia readequar os gastos estatais aos recursos disponíveis para tal tarefa, contando inclusive com certa poupança externa como fonte de auxílio, evitando-se assim as pressões vindas do excesso de meios de pagamento. Sua visão sobre a permissividade dos governos locais estava em certo grau atrelada à atuação do governo peronista, ao qual era um forte opositor (FURTADO, 1985, p. 184).

Imersos neste cenário, um grupo de cepalinos ${ }^{18}$ liderados por Furtado foi incumbido de elaborar uma análise profunda sobre a economia mexicana, no ano de 1956. Ao se debruçarem sobre as questões da economia mexicana, diagnosticaram problemas na composição do conflito social e em seus desníveis de poder, principalmente ligados à dificuldade de relação com o setor exportador, muito dinâmico, porém investido de grande poder político ${ }^{19}$, além da dificuldade inerente à onerosa tentativa de busca pela estabilidade cambial.

O estudo recebeu consecutivas negativas de Prebisch, até que enfim o secretário executivo decidiu por sua não publicação. Esta atitude iria culminar com a saída de Celso Furtado e Juan Noyola Vázquez da CEPAL. Outro acontecimento impor-

\footnotetext{
${ }^{18}$ Além da chefia de Celso Furtado, o grupo ainda contava com a participação de Juan Noyola Vázquez, Osvaldo Sunkel e Oscar Soberón.

${ }^{19}$ Como seria ressaltado no artigo de Noyola para o mesmo ano, ao abordar as peculiaridades dos casos chilenos e mexicanos.
} 
tante para nossa análise foi a visita do economista inglês Nicholas Kaldor à CEPAL, no ano de 1956, com o objetivo de elaborar um sofisticado trabalho sobre a economia chilena. Suas conclusões se aproximaram muito à análise de Furtado e Noyola Vázquez, de modo que, assim como eles, encontrou grande resistência entre a corrente dominante em Santiago ${ }^{20}$.

As dificuldades em publicar seu estudo ainda deflagrariam outros aspectos sobre as tensões internas na CEPAL. Em 1958, foi formalmente decidida a não publicação do artigo em documentos ligados às Nações Unidas, de forma que o trabalho só alcançaria o domínio público em 1959, em edição do El Trimestre Económico.

[...] to put the matter blunty we have decided not to publish your article on Chile. The principal reason is that it has strong political overtones which make it inadvisable to publish it in a UN document [...] in the changed circumstances here in Chile where a new administration is taking over the Government. (Swenson to Kaldor, 25 September 1958 apud PALMA E MARCEL, 1989, p. 248)

Entre os anos de 1957 e 1958, Furtado ${ }^{21}$ vai a Cambridge, a convite de Kaldor, onde tem tempo para desenvolver com maior intensidade as ideias estruturalistas, que agora passam a ter plena independência de seu berço desenvolvimentista cepalino.

A decisão que tomara de afastar-me da CEPAL era menos fruto de decepção do que da consciência de esgotamento do projeto em que me empenhara oito anos atrás. O espaço que tivera diante de mim para explorar parecia esgotado, como se eu o houvesse ocupado em sua plenitude. [...] O que fazemos é essencialmente fruto das circunstâncias, mas há momentos em que já não cabemos nas circunstâncias, começamos a sufocar. Fora para o bem respirar que me libertara da tirania das circunstâncias. (FURTADO, 1985, p. 201)

Quanto à saída da própria corrente estruturalista no último quartil dos anos 1950, muito se alinha a Prebisch (1964, p. 128), quando este nos coloca que nunca

\footnotetext{
${ }^{20}$ Nas palavras de Palma e Marcel (1989, p. 247): “Kaldor's ideas certainly had a 'structuralist' flavor, but they were quite innovative in a period when most Latin American economists within this tradition were emphasising the 'external factors' affecting LDCs. Although Kaldor's stress on the 'internal factors' was received with some scepticism by some leading ECLA economists, he was told that the paper would be published in their Bulletin by the end if the year". O artigo dos autores é fonte necessária para um maior aprofundamento sobre as ideias de Kaldor sobre a economia chilena.

${ }^{21}$ Noyola Vázquez, a partir de 1959 passa a exercer forte influência na política monetária cubana, ao contrário de Furtado, que se retira para comandar a Superintendência do Desenvolvimento do Nordeste - SUDENE. Sua produção, entretanto, é tragicamente interrompida com sua morte em 1962.
} 
houve, na CEPAL, "um pensamento monolítico, neste ou em outros aspectos das 'nossas' atividades intelectuais" (PREBISCH, 1964, p. 128).

Cabe falar de uma escola de pensamento, quiçá a única que haja surgido na América Latina, a qual comporta vertentes diversas, nem sempre conciliáveis em todos os seus aspectos. Casos houve em que um núcleo de ideias se desprendeu do tronco principal, dando lugar a um movimento autônomo, como foi o caso, nos anos 1960, da escola da “dependência" [...]. O mesmo se pode dizer do 'estruturalismo' cepalino, enfoque metodológico que serviu de embasamento para reformas sociais e políticas de enorme alcance. (FURTADO, 2014, p. 99)

Nesse período de acaloradas discussões, em um ambiente intelectual recheado pelos chamados keynesianos de esquerda, Furtado encontra o caminho para sintetizar seus então recentes estudos teóricos, elaborados no ceio da CEPAL, em conjunto com uma análise profunda sobre a formação da economia brasileira. Com acesso a quantidade expressiva de dados, sua síntese entre a história e a teoria econômica da origem à primeira edição do célebre Formação Econômica do Brasil, considerado por muitos uma das obras máximas do estruturalismo latino-americano.

Os problemas criados pela propensão ao desequilíbrio externo, inclusive a inflação estrutural, eram considerados a partir das análises apresentadas em minhas publicações anteriores, concluindo com uma visão prospectiva. O quadro final partia das inter-relações entre os dois centros dinâmicos: o comércio exterior e o mercado interno. (FURTADO, 1985, p. 213)

E ainda ressalta:

As rigidezes estruturais retardariam, até entrado o século $\mathrm{XX}$, o processo de industrialização. Para absorver o atraso acumulado fazia-se necessário um esforço considerável, que o país ainda não se decidira a cometer. Essas hipóteses tinham sentido se apresentadas como um conjunto. Eu assumia a plena responsabilidade de sua formulação. (FURTADO, 1985, p. 216, grifo nosso)

Quanto a Prebisch, no conflituoso período que se sucedeu ao afastamento de Noyola e Furtado até meados de 1961, manteve-se fiel à ideologia original de seu manifesto, concedendo aos demais pontos de sua doutrina certo grau de "flexibilidade estratégica”. Estes pontos eram basicamente 1) uma modernização inclusiva nas economias periféricas através da transformação interna da produção, atrelada à industrialização via substituição de importações, 2) a integração regional na América Latina, e 3) a correção das assimetrias geradas pelo comércio internacional. Quanto às demais questões, mantinha-se cauteloso em prol do apoio regional que continuaria a viabilizar a existência do escritório e sua legitimidade internacional. 


\section{CONCLUSÃO}

Dadas as diferentes abordagens metodológicas e teóricas por parte dos cepalinos ao tratar da questão da estabilidade monetária, o artigo permite a conclusão de que o pensamento cepalino, em seus momentos iniciais, configurava-se heterogêneo no tocante às causas e às terapias de controle da inflação crônica vigente nos países latino-americanos nas décadas de 1950 e 1960. Estas diferenças residiam fundamentalmente na posição mais radical tomada por Prebisch ao negar a possibilidade de certo patamar inflacionário ser inerente ao desenvolvimento econômico, como argumentavam os jovens estruturalistas. Para este autor, tal problema deveria ser combatido de maneira severa, pois os impactos negativos, visíveis nas camadas mais "superficiais" do processo inflacionário são extremamente punitivos para as classes mais baixas. Mesmo admitindo o papel das tensões estruturais, Prebisch se mantinha cético quanto à permissividade dos governos em gerar certa "propensão estrutural à inflação", como identificado por Oliveira (1967).

A localização histórico-institucional do argumento de Prebisch evidencia ainda que parte de sua crença na eficácia de políticas visando estabilidade monetária estava atrelada às tensões em que a CEPAL, como instituição, estava imersa. A necessidade de apoio local condicionava parte de suas medidas à vertente ideológica dominante, representada pelo FMI para medidas anti-inflacionárias ligadas às posições ortodoxas muito presentes nestes países. A solução encontrada fora a adaptação de questões não ligadas ao núcleo da teoria cepalina, apresentada no "manifesto" de Prebisch em 1949, enquanto se mantinha fiel a seus postulados originais. Desta maneira, haveria um conflito inevitável entre os defensores da recente visão estruturalista e aqueles que se alinhavam ao centro do pensamento cepalino.

Tal contraposição à abordagem de Prebisch, defendida pela corrente formada pelos jovens estruturalistas Furtado e Noyola, atribuía aos estrangulamentos estruturais o papel de pressão inflacionária básica. Estas pressões levavam ao desequilíbrio dos preços relativos, que se alastravam pelo sistema principalmente através da expansão passiva da moeda, levando à elevação geral dos preços. Neste cenário, as políticas de contenção monetária eram ineficazes, dada sua incapacidade de realizar as transformações estruturais responsáveis pelo fim dos estrangulamentos setoriais. Muito embora se alegasse a existência de "sentimentos inflacionistas" por parte de tal corrente, o que se constata com a releitura de suas contribuições é que, uma vez observada a inconsistência entre a defesa da estabilidade monetária e o processo de superação da condição periférica, deve-se buscar um conjunto de políticas que vise à continuidade do processo de desenvolvimento (único caminho para a real solução das causas primárias da inflação), aliado ao aumento dos repasses do Estado para as classes menos favorecidas de modo a neutralizar os efeitos danosos de tal fenômeno sobre o conflito distributivo.

Este cenário intelectual e político levava naturalmente às tensões dentro da própria CEPAL, as quais polarizavam a organização. Este tipo de divergência figurava, por um lado, como um ponto positivo para o desenvolvimento de novas 
ideias, estimulando assim maiores reflexões sobre os problemas destes países por tal prisma, à época ainda muito pouco explorado. Entretanto, a impossibilidade de constituição de um corpus teórico heterodoxo uniforme capaz de oferecer soluções consistentes de política econômica para o crônico problema da inflação na região culminou em uma ruptura no canal responsável pela conexão entre o plano das ideias e a tomada de decisões efetivas sobre a condução da economia nacional. Tal perspectiva pode ser atestada pelo fato de que ao longo desse período não se observou a prática das medidas propostas por autores estruturalistas por um intervalo razoavelmente contínuo (a passagem de Celso Furtado pelo governo em 1963 com seu Plano Trienal foi abruptamente interrompida pelo momento político conturbado no Brasil que culminou com o golpe militar de 1964), capaz de fornecer maiores evidências sobre a efetividade prática de suas proposições, sendo este espaço gradativamente preenchido por ideias ligadas à corrente dominante.

\section{REFERÊNCIAS BIBLIOGRÁFICAS}

AUJAC, Henri [1950] 1954. "Inflation as the monetary consequence of the behavior of social groups". International Economic Papers 4: 109-23;

BAER, Werner (1962). "The economics of Prebisch and ECLA". Economic Development and Cultural Change, Vol. 10, No. 2, Part 1 (Jan.), pp. 169-182;

BAER, Werner (1967). "The inflation controversy in Latin America: A Survey". Latin American Research Review, Vol. 2, No. 2 (spring), pp. 3-25;

BAER, Werner (org), KERSTENETZKY, Isaac (org) (1964). Inflation and Growth in Latin America. New Haven: The Economic Growth Center - Yale;

BECKERMAN, Paul (1962). The Economic of High Inflation. Londres: Macmillan;

BLAUG, Mark (1999). Metodologia da Economia ou Como os Economistas Explicam. 2ed. São Paulo: Edusp (Biblioteca EDUSP de economia);

BIELSCHOWSKY, Ricardo (1995). Pensamento Econômico Brasileiro: o Ciclo Ideológico do Desenvolvimentismo. 2ed. Rio de Janeiro: Contraponto;

BOIANOVSKY, Mauro (2012). "Furtado and the structuralist-monetarist debate on economic stabilization in Latin America". History of Political Economy 44.2;

BOIANOVSKY, Mauro; SOLÍS, Ricardo (2014). "The origins and development of the Latin American structuralist approach to the balance of payments, 1944-1964”. Review of Political Economy 26.1 (2014): 23-59;

CALDENTEY, Esteban Pérez; VERNENGO, Matías (2013). "Wage and profit-led growth: the limits to neo-Kaleckian models and a Kaldorian proposal” (October 10). Levy Economics Institute, Working Papers No. 775;

CAMPOS, Roberto Oliveira. (1961) “Two views on inflation in Latin America”. In: HIRSCHMAN, Albert O. (org). Latin American Issues: essays and comments. New York: The twentieth century fund;

COLISTETE, Renato Perim (2007). "Desenvolvimento cepalino: problemas teóricos e influências no Brasil”. In SZMRECASÁNYI, Tamás, COELHO, Francisco da Silva, orgs. Ensaios de História do Pensamento Econômico no Brasil Contemporâneo. São Paulo: Atlas, 2007, p. 27-37;

CRAVEN, Carolyn (1994). A transformation problem: monetarism to structuralism in the economic commission for Latin America". History of Political Economy (Spring), 26(1): 1-19;

DANBY, Colin (2005). "Noyola's institutional approach to inflation". Journal of the History of Economic Thought 27:2 (June), 161-178; 
DOSMAN, Edgar J (2011). Raúl Prebisch (1901-1986): A Construção da América Latina e do Terceiro Mundo. Rio de Janeiro: Contraponto. Centro Internacional Celso Furtado;

DOSMAN, Edgar J(2012). Raúl Prebisch (1901-1986) Santiago: CEPAL, pp. 5-21;

ELLIS, Howard S; WALLICH, Henry C (1961). Desenvolvimento Econômico para a America Latina. Rio De Janeiro: Fundo de cultura, (Biblioteca fundo de cultura);

FONSECA, Pedro C. Dutra (2000). “As origens formadoras do pensamento cepalino”. Revista Brasileira de Economia. Rio de janeiro, RBE, 54(3): 333-358, jul./set;

FÜRSTENAU, Vivian (1981). “Inflação: monetaristas e estruturalistas”. Ensaios FEE, 2(2):25-35;

FURTADO, Celso (1951). "Formação de capital e desenvolvimento econômico" Revista Brasileira de Economia;

FURTADO, Celso (1954). Economia Brasileira: Contribuição a Analise do seu Desenvolvimento. Rio De Janeiro: A Noite;

FURTADO, Celso (1959c). "Ninguna política esta justificada como no sea en virtud del desarrollo económico del país”. El Trimestre Económico: 136-140;

FURTADO, Celso (1985). Fantasia Organizada. 5ed. Rio De Janeiro: Paz e Terra;

FURTADO, Celso (2000). Teoria e Política do Desenvolvimento Econômico. 10ed. São Paulo: Paz e Terra;

FURTADO, Celso (2009). Desenvolvimento e Subdesenvolvimento. 5ed. Rio De Janeiro: Contraponto; HAGGER, Alfred James (1977). Inflation: Theory and Policy. London: Macmillan;

HIRSCHMAN, Albert O (1967). Monetarismo VS. Estruturalismo: um Estudo sobre a America Latina. Rio De Janeiro: Agencia Norte Americana para o desenvolvimento internacional;

JAMESON, Kenneth P (1986). “Latin American structuralism: a methodological perspective”. World Development, Volume 14, Issue 2, February, Pages 223-242;

KEYNES, John Maynard (1919 [2002]). As Consequências Econômicas da Paz. São Paulo: Editora Universidade de Brasília;

KEYNES, John Maynard (1940). How to Pay for the War: a Radical Plan for the Chancellor of the Exchequer. London: Macmillan And Co., Limited.;

NOYOLA VÁZQUEZ, Juan F (1949b). Desequilibrio Fundamental y Fomento Económico en México. Tesis para grado de Licenciado de Economía, UNAM, Escuela Nacional de Economía;

NOYOLA VÁZQUEZ, Juan F (1956). "El desarrollo económico y la inflación en México y otros países Latinoamericanos". Investigación Económica. XVI: 4;

OLIVERA, Julio (1964). “On structural inflation and Latin-American 'structuralism'. “ 16: 321-32;

OLIVERA, Julio (1964). “Aspectos dinámicos de la inflación estrutural”. Desarrollo Económico. 7: 261- 266;

Palma, José Gabriel; Marcel, Mario (1989). "Kaldor on the 'discret charm' of the Chilean bourgeoisie”. Cambridge Journal of Economics 13(1), pp. 245-272;

PALMA, José Gabriel (2014). Latin America's Social imagination since 1950. From one type of "absolute certainties" to another-with no (far more creative) "uncomfortable uncertainties" in sight. No 1416. Faculty of Economics, University of Cambridge;

PAZOS, Felipe (1972c). Chronic Inflation in Latin America. New York: Praeger. (Praeger special studies in international economics and development);

PERINGER, Alfredo M (1985). Monetarismo vs Keynesianismo vs Estruturalismo: Inflação, Desemprego e Taxas de Juros. Rio de Janeiro: Globo.

PREBISCH, Raúl (1961). "El falso dilema entre desarrollo económico y estabilidad monetaria”. Boletín Económico de América Latina vol. VI, No.1, (Março) pp. 1-27;

PREBISCH, Raúl (1964). Dinâmica do Desenvolvimento Latino-Americano. Rio de Janeiro: Fundo de cultura. (Perspectivas do nosso tempo);

PREBISCH, Raúl (1982). “Monetarísmo, aperturismo y crisis ideológica”. Revista de la CEPAL, n 17 (Agosto);

PREBISCH, Raúl (1949 [2000]). “O desenvolvimento econômico da América Latina e Alguns de seus 
problemas principais”. In BIELSCHOWSKY, R. (org.) Cinqüenta anos de pensamento na CEPAL. Rio de Janeiro: Record;

SALANT, Walter S; KRAUSE, Lawrence B (1977). Worldwide Inflation: Theory and Recent Experience. Washington D.C.: Brookings Institution;

SIMONSEN, Mário Henrique (1970). Inflação: Gradualismo x Tratamento de Choque. Rio de Janeiro: Anpec;

SUNKEL, Osvaldo (1958). "La Inflación Chilena: un Enfoque Heterodoxo”. El trimestre Económico, vol. 25(4), nº 100. Outubro-Dezembro; 